\title{
Development of chiral metal amides as highly reactive catalysts for asymmetric [3 + 2] cycloadditions
}

\author{
Yasuhiro Yamashita, Susumu Yoshimoto, Mark J. Dutton and Shū Kobayashi ${ }^{*}$
}

\author{
Letter \\ Address: \\ Department of Chemistry, School of Science, The University of Tokyo, \\ Hongo, Bunkyo-ku, Tokyo, Japan \\ Email: \\ Shū Kobayashi* - shu_kobayashi@chem.s.u-tokyo.ac.jp \\ * Corresponding author \\ Keywords: \\ [3 + 2] cycloaddition; asymmetric reaction; catalytic reaction; low \\ catalyst loading; metal amide
}

Beilstein J. Org. Chem. 2016, 12, 1447-1452.

doi:10.3762/bjoc. 12.140

Received: 28 March 2016

Accepted: 02 June 2016

Published: 13 July 2016

This article is part of the Thematic Series "Strategies in asymmetric catalysis".

Guest Editor: T. P. Yoon

(C) 2016 Yamashita et al.; licensee Beilstein-Institut.

License and terms: see end of document.

\begin{abstract}
Highly efficient catalytic asymmetric [3 + 2] cycloadditions using a chiral copper amide are reported. Compared with the chiral $\mathrm{CuOTf} / \mathrm{Et}_{3} \mathrm{~N}$ system, the CuHMDS system showed higher reactivity, and the desired reactions proceeded in high yields and high selectivities with catalyst loadings as low as $0.01 \mathrm{~mol} \%$.
\end{abstract}

\section{Findings}

Catalytic asymmetric synthesis is an ideal method to prepare optically active compounds [1]. In this context, catalytic asymmetric carbon-carbon bond-forming reactions that can be used for the efficient construction of fundamental frameworks of complex chiral molecules such as biologically active compounds are particularly important. Chiral Lewis acid/Brønsted base-catalyzed carbon-carbon bond-forming reactions are one of the most efficient methods from the viewpoint of atom economy because only proton transfer occurs between starting materials and target products [2]. Several kinds of chiral Lewis acid/Brønsted base-catalyst systems have been developed; however, decreasing the catalyst loading is sometimes problematic either because of the low reactivity of catalysts or because the catalyst activity can be reduced through Lewis acid-Lewis base interaction between catalysts and the formed products (product inhibition). To overcome such issues, the design and development of more reactive catalysts is required.

Our group has focused on the development of metal amides as highly reactive Lewis acid/base catalysts in carbon-carbon bond-forming reactions [3]. Recently, we have developed asymmetric [3+2] cycloadditions [4-8] and asymmetric Mannichtype reactions [9] by using chiral silver or copper amides as catalysts. In these reactions, it has been revealed that the metal amides have higher activity than typical silver or copper acid/ base catalysts, and that less reactive substrates react smoothly to 
afford the desired products in high yields with high stereoselectivities. Based on these results, it was considered that metal amide catalysts might also achieve high catalyst turnover. Here, we report chiral copper amide-catalyzed asymmetric $[3+2]$ cycloadditions of Schiff bases of glycine ester that proceed with low catalyst loadings (ca. $0.01 \mathrm{~mol} \%$ ).

Catalytic asymmetric [3 +2$]$ cycloadditions of Schiff bases of $\alpha$-amino esters to olefins are useful for synthesizing optically active pyrrolidine derivatives [10-12], and many highly stereoselective reactions have been reported; for example, Co [13], $\mathrm{Cu}$ [14-23], Ag [24-32], Zn [33,34], Ni [35,36], and Ca [37-39] catalyst systems, and organocatalysts [40-45] have been successfully employed. In most cases, however, relatively high catalyst loadings $(0.5-25 \mathrm{~mol} \%)$ are required to achieve high yield and selectivities $[15,45]$. First, we investigated the catalytic asymmetric [3+2] cycloaddition of Schiff base 1a, prepared from glycine methyl ester and benzaldehyde, with $\mathrm{N}$-phenylmaleimide (2a) in the presence of $\mathrm{CuN}\left(\mathrm{SiMe}_{3}\right)_{2}$ (CuHMDS) and the FeSulphos ligand, with the latter being related to the system reported by Carretero et al. [15]. The reaction produced 3aa smoothly with $3 \mathrm{~mol} \%$ catalyst loading at $-40^{\circ} \mathrm{C}$, and high endo selectivity and high enantioselectivity were obtained (Table 1, entry 1). On the other hand, application of CuOTf, FeSulphos, and $\mathrm{Et}_{3} \mathrm{~N}$ gave only $47 \%$ yield of the product (Table 1, entry 2). This result indicated that the CuHMDS catalyst had higher catalyst activity than CuOTf with the additional amine base. The copper amide catalyst also showed high reactivity and selectivity with $1 \mathrm{~mol} \%$ catalyst loading (Table 1 , entry 3 ), and similar results were obtained in other solvents such as $\mathrm{Et}_{2} \mathrm{O}$ and toluene, although the reactivity and enantioselectivity both decreased slightly in dichloromethane (DCM, Table 1, entries 4-6). It was found that the use of the chiral CuHMDS catalyst also afforded the product with high enantioselectivity at lower catalyst loadings of $0.1 \mathrm{~mol} \%$ (Table 1 , entry 7). The effect of the amide part of the structure was then examined. Copper dialkylamides were not as reactive as CuHMDS, and lower yields were obtained (Table 1, entries 8 and 9). Interestingly, mesitylcopper also worked in a similar fashion, and good yields and high selectivities were obtained (Table 1, entry 10). This result indicated that the reaction proceeded through a product base mechanism [46-48]; however, the reactivity was lower than that of the CuHMDS system. Decreasing the catalyst loading further revealed that the reaction

Table 1: Chiral copper amide-catalyzed asymmetric [3+2] cycloadditions ${ }^{a}$

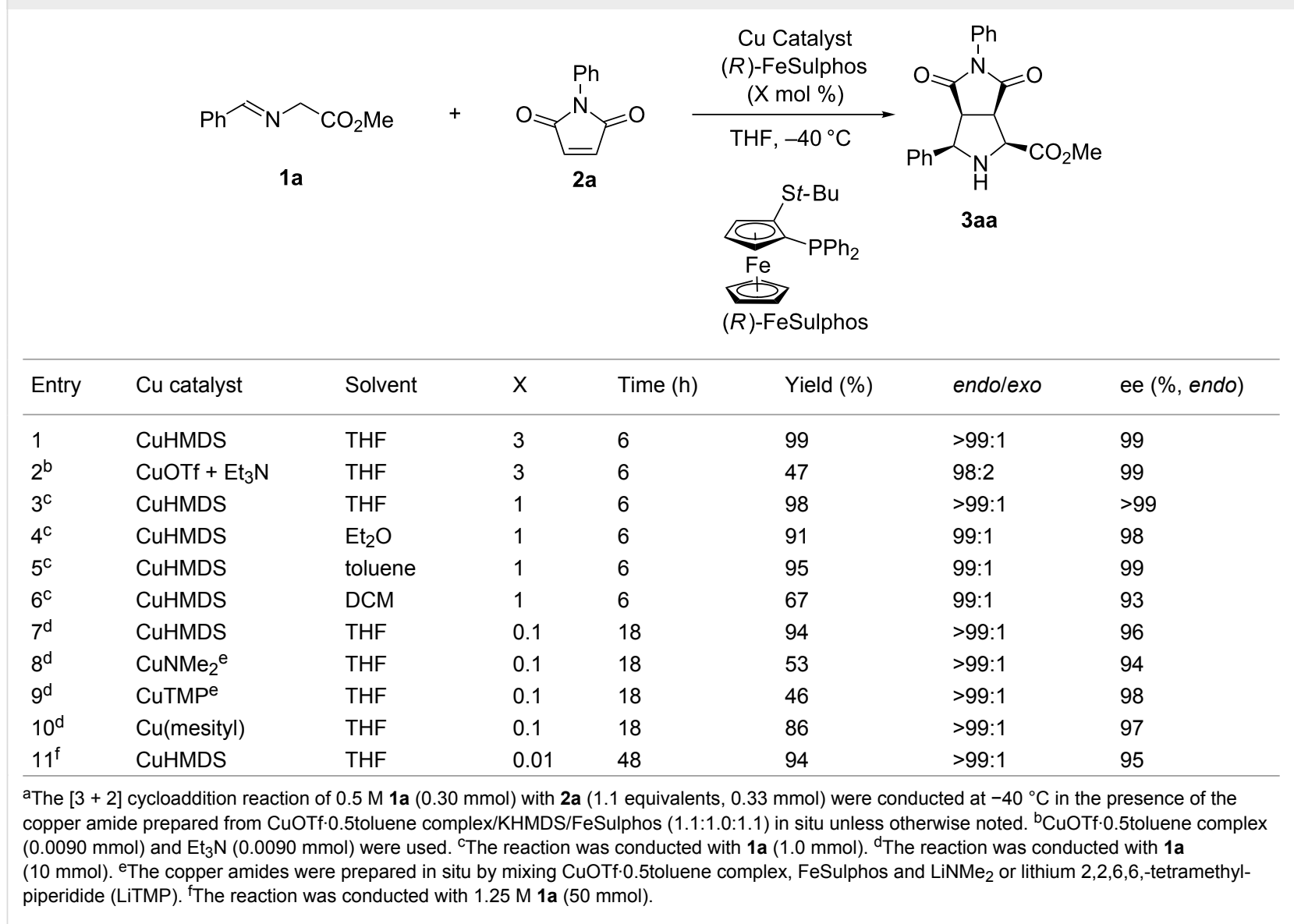


proceeded with $0.01 \mathrm{~mol} \%$ loading of chiral CuHMDS catalyst without significant loss of selectivity (Table 1, entry 11).

We then examined the substrate scope of the $[3+2]$ cycloaddition with respect to the Schiff base (Table 2). The Schiff bases prepared from tolualdehydes were successfully employed in the reaction with $\mathbf{2 a}$, and high reactivities and enantioselectivities were observed by using $0.1 \mathrm{~mol} \%$ catalyst loading (Table 2 , entries 1-4). The Schiff base from $p$-methoxybenzaldehyde was a good substrate (Table 2, entry 5 ) and reacted even in the presence of $0.01 \mathrm{~mol} \%$ catalyst loading, albeit with a slight decrease in the enantioselectivity (Table 2 , entry 6 ). The use of Schiff bases bearing either electron-donating or electron-withdrawing substituents were also suitable, and high yields and enantioselectivities were obtained with both 0.1 and $0.01 \mathrm{~mol} \%$ catalyst loading (Table 2, entries 5-9). Sterically hindered substrates were also viable, and high enantioselectivities were obtained with $0.01 \mathrm{~mol} \%$ catalyst loading (Table 2, entries 10-13).

Other electrophiles were also successfully employed with $0.1 \mathrm{~mol} \%$ catalyst loading (Scheme 1 ). $N$-Methylmaleimide reacted with 1a in high yield with high diastereo- and enantiose- lectivities. The reaction with methyl acrylate also proceeded in high yield with high enantioselectivity; however, in this case the exo/endo selectivity was moderate. Methyl vinyl ketone and methyl methacrylate reacted with $\mathbf{1 a}$ to afford the desired $[3+2]$ adducts in high yields with high selectivities. Notably, the chiral CuHMDS catalyst worked well with catalyst loadings of both 0.1 and $0.01 \mathrm{~mol} \%$.

A proposed catalytic cycle is shown in Figure 1. Thus, the chiral CuHMDS deprotonates Schiff base 1a to generate the corresponding chiral $\mathrm{Cu}$ enolate $\mathbf{B}$ through the efficient formation of pseudo-intramolecular transition state A. Intermediate $\mathbf{B}$ reacted with maleimide 2a to form $\mathrm{Cu}$-pyrrolidine intermediate C. H-HMDS then reacted with the latter to regenerate the chiral CuHMDS and release the product to complete the catalytic cycle. The result obtained by using a mesitylcopper catalyst suggests that the reaction could also proceed through a product base mechanism in which the $\mathrm{Cu}$-pyrrolidine intermediate $\mathbf{C}$ deprotonates the Schiff base 1a directly; however, the higher reactivity observed upon catalysis by CuHMDS and the basicity of the intermediate indicates that the proposed cycle is reasonable when CuHMDS is used as catalyst. The high catalyst turnover may be due to the stronger Brønsted basicity of

Table 2: Scope of the reaction with respect to Schiff bases ${ }^{a}$.

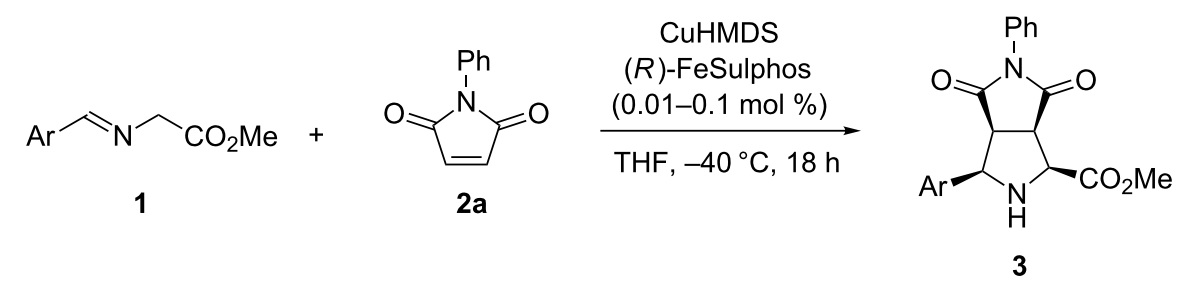

\begin{tabular}{|c|c|c|c|c|c|c|c|}
\hline Entry & $\mathrm{Ar}$ & 1 & FeSulphos (mol \%) & 3 & Yield (\%) & Endolexo & ee $(\%$, endo $)$ \\
\hline 1 & $p-\mathrm{MeC}_{6} \mathrm{H}_{4}$ & $1 b$ & 0.1 & 3 ba & 92 & $>99: 1$ & $>99$ \\
\hline 2 & $p-\mathrm{MeC}_{6} \mathrm{H}_{4}$ & $1 b$ & 0.01 & $3 b a$ & 91 & $>99: 1$ & 85 \\
\hline 3 & $m-\mathrm{MeC}_{6} \mathrm{H}_{4}$ & $1 c$ & 0.1 & $3 c a$ & 93 & $>99: 1$ & $>99$ \\
\hline 4 & $o-\mathrm{MeC}_{6} \mathrm{H}_{4}$ & $1 d$ & 0.1 & $3 \mathrm{da}$ & 92 & $97: 3$ & $>99$ \\
\hline 5 & $p-\mathrm{MeOC}_{6} \mathrm{H}_{4}$ & $1 e$ & 0.1 & 3ea & 91 & $97: 3$ & 99 \\
\hline 6 & $p-\mathrm{MeOC}_{6} \mathrm{H}_{4}$ & $1 e$ & 0.01 & $3 e a$ & 91 & $>99: 1$ & 93 \\
\hline 7 & $p-\mathrm{ClC}_{6} \mathrm{H}_{4}$ & $1 f$ & 0.1 & $3 f a$ & 96 & $98: 2$ & 92 \\
\hline 8 & $p-\mathrm{FC}_{6} \mathrm{H}_{4}$ & $1 \mathrm{~g}$ & 0.1 & $3 g a$ & 96 & $>99: 1$ & 99 \\
\hline 9 & $p-\mathrm{FC}_{6} \mathrm{H}_{4}$ & $1 \mathrm{~g}$ & 0.01 & $3 g a$ & 96 & $>99: 1$ & 98 \\
\hline 10 & 2-naphthyl & $1 \mathrm{~h}$ & 0.1 & 3ha & 94 & $>99: 1$ & 99 \\
\hline 11 & 2-naphthyl & $1 \mathrm{~h}$ & 0.01 & 3ha & 87 & $>99: 1$ & 97 \\
\hline 12 & 1-naphthyl & $1 \mathbf{i}$ & 0.1 & $3 i a$ & 76 & $>99: 1$ & 99 \\
\hline 13 & 1-naphthyl & $1 \mathbf{i}$ & 0.01 & $3 i a$ & 91 & $>99: 1$ & 98 \\
\hline
\end{tabular}

aReaction conditions: For $0.1 \mathrm{~mol} \%$ catalyst loading: the [3+2] cycloaddition reactions of $0.5 \mathrm{M} 1(10 \mathrm{mmol})$ with $2 \mathrm{a}(11 \mathrm{mmol})$ were conducted at $-40{ }^{\circ} \mathrm{C}$ for $18 \mathrm{~h}$ by using the chiral copper amide prepared from CuOTf.0.5toluene complex ( $\left.0.011 \mathrm{mmol}\right)$, KHMDS (0.010 mmol), and FeSulphos $(0.011 \mathrm{mmol})$ in situ. For $0.01 \mathrm{~mol} \%$ catalyst loading: the [3 + 2] cycloaddition reactions of $1.25 \mathrm{M} 1(50 \mathrm{mmol})$ with $2 \mathrm{a}(55 \mathrm{mmol})$ were conducted at $-40{ }^{\circ} \mathrm{C}$ for $48 \mathrm{~h}$ by using the chiral copper amide prepared from CuOTf 0.5 toluene complex ( $\left.0.0055 \mathrm{mmol}\right)$, KHMDS (0.0050 mmol), and FeSulphos $(0.0055 \mathrm{mmol})$ in situ. 


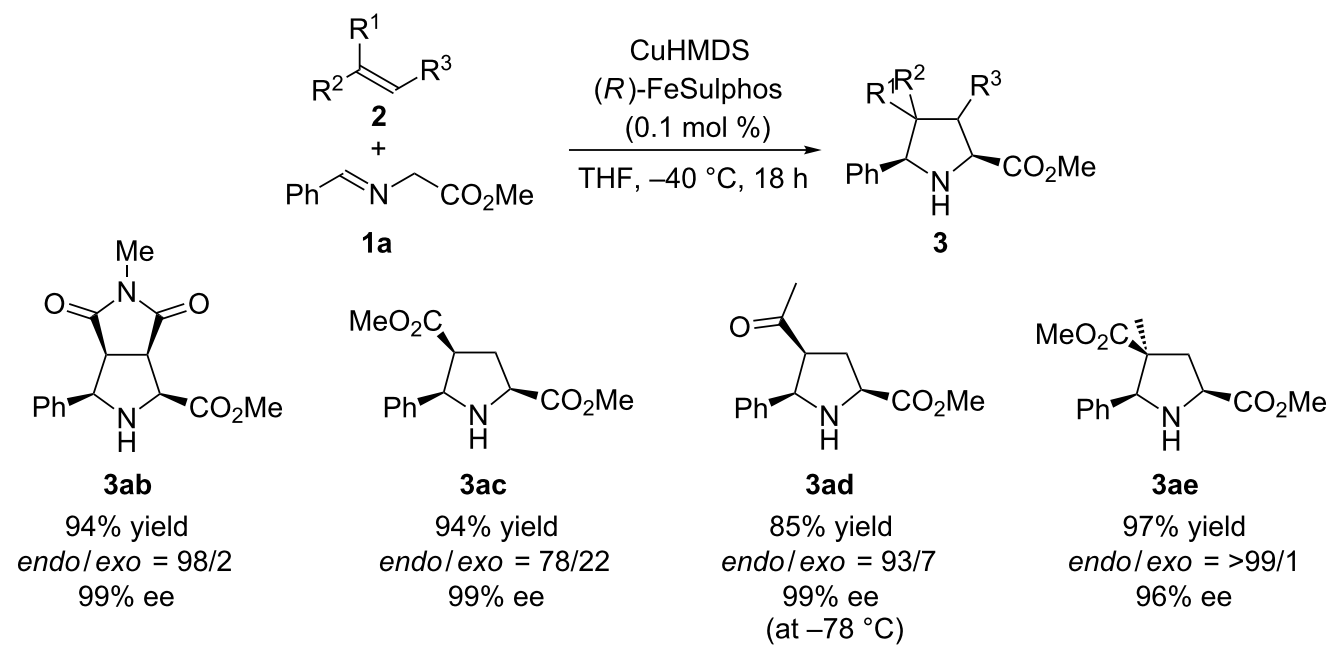

Scheme 1: Scope of the reaction with other electrophiles. The [3+2] cycloaddition reaction of $0.5 \mathrm{M} 1 \mathrm{a}(10 \mathrm{mmol})$ with 2 (11 mmol) was conducted at $-40{ }^{\circ} \mathrm{C}$ for $18 \mathrm{~h}$ by using the chiral copper amide prepared from CuOTf.0.5toluene complex ( $\left.0.011 \mathrm{mmol}\right)$, KHMDS (0.010 mmol), and FeSulphos $(0.011 \mathrm{mmol})$ in situ.

CuHMDS, which enables rapid deprotonation of the Schiff base.

\section{Conclusion}

In conclusion, highly efficient asymmetric $[3+2]$ cycloadditions catalyzed by chiral CuHMDS have been described. Com- pared with catalysis by using the $\mathrm{CuOTf} / \mathrm{Et}_{3} \mathrm{~N}$ system, the $\mathrm{Cu}$ amide system showed higher reactivity, and the reactions proceeded with high enantioselectivities even with $0.01 \mathrm{~mol} \%$ catalyst loading. Further investigations that are focused on the application of metal amide catalysts in other reactions are ongoing.

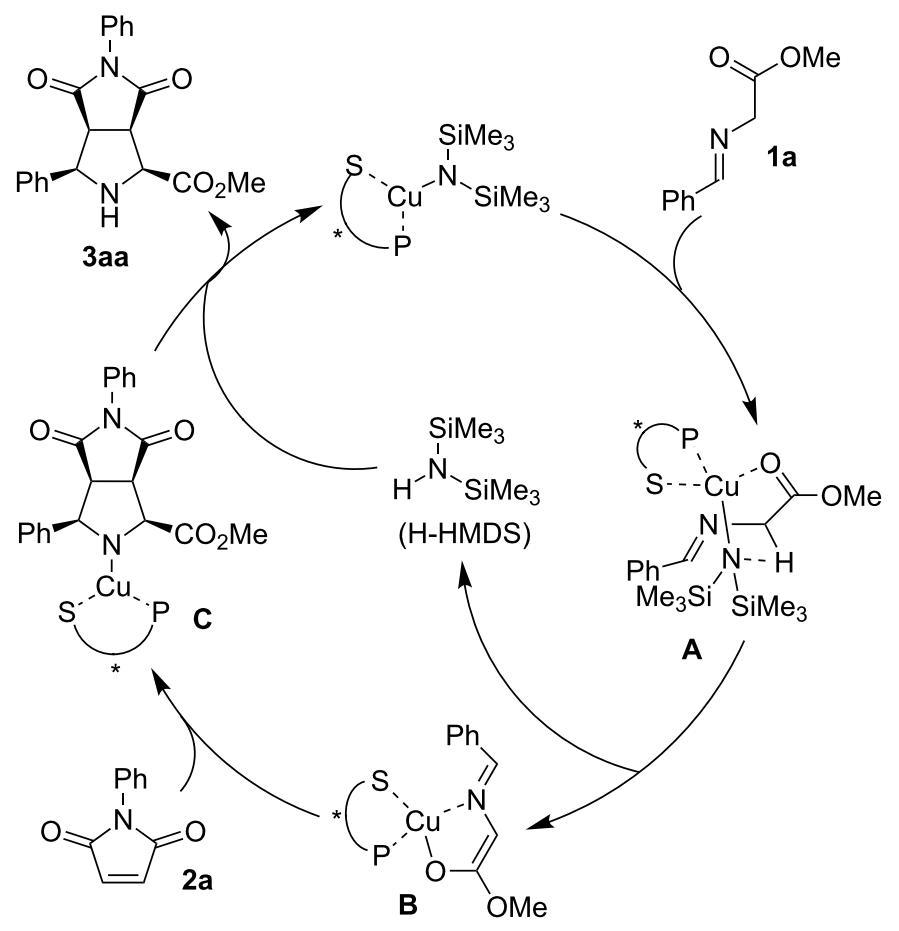

Figure 1: Proposed catalytic cycle. 


\section{Experimental}

A general experimental procedure for conducting catalytic asymmetric $[3+2]$ cycloaddition reactions with $0.01 \mathrm{~mol} \%$ catalyst loading is described. Under an Ar atmosphere, a solution of the preformed chiral CuHMDS catalyst [prepared from KHMDS ( $1.0 \mathrm{mg}, 0.0050 \mathrm{mmol})$, CuOTf $\cdot 0.5$ toluene $(1.3 \mathrm{mg}$, $0.0055 \mathrm{mmol})$ and FeSulphos $(2.3 \mathrm{mg}, 0.0050 \mathrm{mmol})$ in anhydrous THF $(5 \mathrm{~mL})$ with heating at $40{ }^{\circ} \mathrm{C}$ for $1 \mathrm{~h}$ ] was transferred into a well-dried $50 \mathrm{~mL}$ single-necked flask attached to a three-way cock (sealed with grease). The solution was cooled at $-40{ }^{\circ} \mathrm{C}$, and a mixture of $1(50 \mathrm{mmol})$ and $\mathbf{2 a}(55 \mathrm{mmol})$ in anhydrous THF $(35 \mathrm{~mL})$ was added by using a cannula. The whole was stirred for $48 \mathrm{~h}$ at $-40{ }^{\circ} \mathrm{C}$, then the reaction was quenched by the addition of $\mathrm{H}_{2} \mathrm{O}$, and the mixture was extracted with dichloromethane. The organic layers were combined and dried over anhydrous $\mathrm{Na}_{2} \mathrm{SO}_{4}$. The selectivities were determined by ${ }^{1} \mathrm{H}$ NMR analysis and HPLC analysis after purification of a small amount of the separated crude solution. After filtration and concentration under reduced pressure, the crude product obtained was purified by recrystallization and column chromatography to determine the isolated yield of the desired product. Obtained compounds were characterized by ${ }^{1} \mathrm{H}$ and ${ }^{13} \mathrm{C}$ NMR and by HPLC analyses using HPLC with chiral columns. The physical data for the products were consistent with reported values [49-54].

\section{Acknowledgements}

This work was partially supported by a Grant-in-Aid for Science Research from the Japan Society for the Promotion of Science (JSPS), Global COE Program, the University of Tokyo, MEXT, Japan, and the Japan Science and Technology Agency (JST). S. Y. thanks the MERIT program, University of Tokyo, for financial support.

\section{References}

1. Ojima, I., Ed. Catalytic Asymmetric Synthesis, 3rd ed.; John Wiley \& Sons, Inc.: Hoboken, New Jersey, 2010. doi:10.1002/9780470584248

2. Kumagai, N.; Shibasaki, M. Angew. Chem., Int. Ed. 2011, 50, 4760-4772. doi:10.1002/anie.201100918

3. Yamashita, Y.; Kobayashi, S. Chem. - Eur. J. 2013, 19, 9420-9427. doi:10.1002/chem.201300908

4. Yamashita, Y.; Guo, X.-X.; Takashita, R.; Kobayashi, S. J. Am. Chem. Soc. 2010, 132, 3262-3263. doi:10.1021/ja100101n

5. Yamashita, Y.; Imaizumi, T.; Guo, X.-X.; Kobayashi, S. Chem. - Asian J. 2011, 6, 2550-2559. doi:10.1002/asia.201100246

6. Yamashita, Y.; Imaizumi, T.; Kobayashi, S. Angew. Chem., Int. Ed. 2011, 50, 4893-4896. doi:10.1002/anie.201008272

7. Imaizumi, T.; Yamashita, Y.; Kobayashi, S. J. Am. Chem. Soc. 2012, 134, 20049-20052. doi:10.1021/ja311150n

8. Yamashita, Y.; Nam, L. C.; Dutton, M. J.; Yoshimoto, S.; Kobayashi, S. Chem. Commun. 2015, 51, 17064-17067. doi:10.1039/C5CC07066J

9. Yamashita, Y.; Yoshimoto, S.; Masuda, K.; Kobayashi, S. Asian J. Org. Chem. 2012, 1, 327-330. doi:10.1002/ajoc.201200092
10. Adrio, J.; Carretero, J. C. Chem. Commun. 2011, 47, 6784-6794. doi:10.1039/c1cc10779h

11. Adrio, J.; Carretero, J. C. Chem. Commun. 2014, 50, 12434-12446. doi:10.1039/C4CC04381B

12. Hashimoto, T.; Maruoka, K. Chem. Rev. 2015, 115, 5366-5412. doi:10.1021/cr5007182

13. Allway, P.; Grigg, R. Tetrahedron Lett. 1991, 32, 5817-5820. doi:10.1016/S0040-4039(00)93563-9

14. Oderaotoshi, Y.; Cheng, W.; Fujitomi, S.; Kasano, Y.; Minakata, S.; Komatsu, M. Org. Lett. 2003, 5, 5043-5046. doi:10.1021/ol036076s

15. Cabrera, S.; Arrayás, R. G.; Carretero, J. C. J. Am. Chem. Soc. 2005, 127, 16394-16395. doi:10.1021/ja0552186

16. Gao, W.; Zhang, X.; Raghunath, M. Org. Lett. 2005, 7, 4241-4244. doi:10.1021/ol0516925

17. Yan, X.-X.; Peng, Q.; Zhang, Y.; Zhang, K.; Hong, W.; Hou, X.-L.; Wu, Y.-D. Angew. Chem., Int. Ed. 2006, 45, 1979-1983. doi:10.1002/anie.200503672

18. Cabrera, S.; Arrayás, R. G.; Martín-Matute, B.; Cossío, F. P.; Carretero, J. C. Tetrahedron 2007, 63, 6587-6602. doi:10.1016/j.tet.2007.03.130

19. Shi, M.; Shi, J.-W. Tetrahedron: Asymmetry 2007, 18, 645-650. doi:10.1016/j.tetasy.2007.02.027

20. Fukuzawa, S.-i.; Oki, H. Org. Lett. 2008, 10, 1747-1750. doi:10.1021/ol8003996

21. Wang, C.-J.; Liang, G.; Xue, Z.-Y.; Gao, F. J. Am. Chem. Soc. 2008, 130, 17250-17251. doi:10.1021/ja807669q

22. Nájera, C.; de Garcia Retamosa, M.; Sansano, J. M. Angew. Chem., Int. Ed. 2008, 47, 6055-6058. doi:10.1002/anie. 200801690

23. Hernández-Toribio, J.; Arrayás, R. G.; Martín-Matute, B.; Carretero, J. C. Org. Lett. 2009, 11, 393-396. doi:10.1021/ol802664m

24. Grigg, R. Tetrahedron: Asymmetry 1995, 6, 2475-2486. doi:10.1016/0957-4166(95)00323-H

25. Longmire, J. M.; Wang, B.; Zhang, X. J. Am. Chem. Soc. 2002, 124 , 13400-13401. doi:10.1021/ja025969x

26. Chen, C.; Li, X.; Schreiber, S. L. J. Am. Chem. Soc. 2003, 125, 10174-10175. doi:10.1021/ja036558z

27. Knöpfel, T. F.; Aschwanden, P.; Ichikawa, T.; Watanabe, T.; Carreira, E. M. Angew. Chem., Int. Ed. 2004, 43, 5971-5973. doi:10.1002/anie.200461286

28. Alemparte, C.; Blay, G.; Jørgensen, K. A. Org. Lett. 2005, 7, 4569-4572. doi:10.1021/ol0514653

29. Zeng, W.; Zhou, Y.-G. Org. Lett. 2005, 7, 5055-5058. doi:10.1021/ol0520370

30. Stohler, R.; Wahl, F.; Pfaltz, A. Synthesis 2005, 1431-1436. doi:10.1055/s-2005-865313

31.Zeng, W.; Chen, G.-Y.; Zhou, Y.-G.; Li, Y.-X. J. Am. Chem. Soc. 2007, 129, 750-751. doi:10.1021/ja067346f

32. Kim, H. Y.; Shih, H.-J.; Knabe, W.-E.; Oh, K. Angew. Chem., Int. Ed. 2009, 48, 7420-7423. doi:10.1002/anie.200903479

33. Gothelf, A. S.; Gothelf, K. V.; Hazell, R. G.; Jørgensen, K. A. Angew. Chem., Int. Ed. 2002, 41, 4236-4238. doi:10.1002/1521-3773(20021115)41:22<4236::AID-ANIE4236>3.0.CO ;2-W

34. Dogan, Ö.; Koyuncu, H.; Garner, P.; Bulut, A.; Youngs, W. J.; Panzner, M. Org. Lett. 2006, 8, 4687-4690. doi:10.1021/ol061521f

35. Shi, J.-W.; Zhao, M.-X.; Lei, Z.-Y.; Shi, M. J. Org. Chem. 2008, 73, 305-308. doi:10.1021/jo701561d

36. Awata, A.; Arai, T. Chem. - Eur. J. 2012, 18, 8278-8282. doi:10.1002/chem.201201249 
37. Saito, S.; Tsubogo, T.; Kobayashi, S. J. Am. Chem. Soc. 2007, 129, 5364-5365. doi:10.1021/ja0709730

38. Tsubogo, T.; Saito, S.; Seki, K.; Yamashita, Y.; Kobayashi, S. J. Am. Chem. Soc. 2008, 130, 13321-13332. doi:10.1021/ja8032058

39. Hut'ka, M.; Tsubogo, T.; Kobayashi, S. Adv. Synth. Catal. 2013, 355, 1561-1569. doi:10.1002/adsc.201300171

40. Vicario, J. L.; Reboredo, S.; Badía, D.; Carrillo, L. Angew. Chem., Int. Ed. 2007, 46, 5168-5170. doi:10.1002/anie.200700988

41. Ibrahem, I.; Rios, R.; Vesely, J.; Córdova, A. Tetrahedron Lett. 2007, 48, 6252-6257. doi:10.1016/j.tetlet.2007.07.031

42. Chen, X.-H.; Zhang, W.-Q.; Gong, L.-Z. J. Am. Chem. Soc. 2008, 130, 5652-5653. doi:10.1021/ja801034e

43. Guo, C.; Xue, M.-X.; Zhu, M.-K.; Gong, L.-Z. Angew. Chem., Int. Ed. 2008, 47, 3414-3417. doi:10.1002/anie.200800003

44. Liu, Y.-K.; Liu, H.; Du, W.; Yue, L.; Chen, Y.-C. Chem. - Eur. J. 2008, 14, 9873-9877. doi:10.1002/chem.200801410

45. Tian, L.; Xu, G.-Q.; Li, Y.-H.; Liang, Y.-M.; Xu, P.-F. Chem. Commun. 2014, 50, 2428-2430. doi:10.1039/c3cc49504c

46. Poisson, T.; Gembus, V.; Oudeyer, S.; Marsais, F.; Levacher, V. J. Org. Chem. 2009, 74, 3516-3519. doi:10.1021/jo802763b

47. Yazaki, R.; Kumagai, N.; Shibasaki, M. Chem. - Asian J. 2011, 6 , 1778-1790. doi:10.1002/asia.201100050

48. Yamashita, Y.; Suzuki, H.; Kobayashi, S. Org. Biomol. Chem. 2012, 10, 5750-5752. doi:10.1039/c2ob25522g

49. Products 3aa, 3da, 3ea, 3ga, 3ha, 3ab, 3ac were reported in ref. [15].

50. Products 3 ba and 3 fa were reported in ref. [19].

51. Product 3ad was reported in ref. [23].

See also Tsuge, O.; Kanemasa, S.; Yoshioka, M. J. Org. Chem. 1998, 53, 1384-1391. doi:10.1021/jo00242a008

52. Product 3ae was reported in ref. [32].

53. Product 3ia was reported in ref. [35].

54. Bai, J.-F.; Wang, L.-L.; Peng, L.; Guo, Y.-L.; Ming, J.-N.; Wang, F.-Y.; Xu, X.-Y.; Wang, L.-X. Eur. J. Org. Chem. 2011, 4472-4478. doi:10.1002/ejoc.201100205

See for product $3 \mathbf{c a}$

\section{License and Terms}

This is an Open Access article under the terms of the Creative Commons Attribution License

(http://creativecommons.org/licenses/by/2.0), which permits unrestricted use, distribution, and reproduction in any medium, provided the original work is properly cited.

The license is subject to the Beilstein Journal of Organic Chemistry terms and conditions:

(http://www.beilstein-journals.org/bjoc)

The definitive version of this article is the electronic one which can be found at: $\underline{\text { doi:10.3762/bjoc. } 12.140}$ 